\title{
Health Gain, Cost Impacts, and Cost-Effectiveness of a Mass Media Campaign to Promote Smartphone Apps for Physical Activity: Modeling Study
}

Anja Mizdrak ${ }^{1}$, BA, DPhil; Kendra Telfer ${ }^{1}$, Hons; Artur Direito ${ }^{2}$, PhD; Linda J Cobiac ${ }^{3}$, PhD; Tony Blakely ${ }^{1,4}$, MBChB, $^{2}$ NZPHM, PhD; Christine L Cleghorn ${ }^{1}$, BSc, MSc, PhD; Nick Wilson ${ }^{1}, \mathrm{MPH}$

\footnotetext{
${ }^{1}$ Department of Public Health, University of Otago Wellington, Wellington, New Zealand

${ }^{2}$ Yong Loo Lin School of Medicine, National University of Singapore, Singapore, Singapore

${ }^{3}$ Nuffield Department of Population Health, University of Oxford, Oxford, United Kingdom

${ }^{4}$ Centre for Epidemiology and Biostatistics, University of Melbourne, Melbourne, Australia
}

\section{Corresponding Author:}

Anja Mizdrak, BA, DPhil

Department of Public Health

University of Otago Wellington

Department of Public Health, 23 Mein Street

Newtown

Wellington, 6021

New Zealand

Phone: 6449186192

Email: anja.mizdrak@otago.ac.nz

\section{Abstract}

Background: Physical activity smartphone apps are a promising strategy to increase population physical activity, but it is unclear whether government mass media campaigns to promote these apps would be a cost-effective use of public funds.

Objective: We aimed to estimate the health impacts, costs, and cost-effectiveness of a one-off national mass media campaign to promote the use of physical activity apps.

Methods: We used an established multistate life table model to estimate the lifetime health gains (in quality-adjusted life years [QALYs]) that would accrue if New Zealand adults were exposed to a one-off national mass media campaign to promote physical activity app use, with a 1-year impact on physical activity, compared to business-as-usual. A health-system perspective was used to assess cost-effectiveness. and a 3\% discount rate was applied to future health gains and health system costs.

Results: The modeled intervention resulted in 28 QALYs (95\% uncertainty interval [UI] 8-72) gained at a cost of NZ $\$ 81,000 /$ QALY (2018 US \$59,500; 95\% UI 17,000-345,000), over the remaining life course of the 2011 New Zealand population. The intervention had a low probability (20\%) of being cost-effective at a cost-effectiveness threshold of NZ \$45,000 (US \$32,900) per QALY. The health impact and cost-effectiveness of the intervention were highly sensitive to assumptions around the maintenance of physical activity behaviors beyond the duration of the intervention.

Conclusions: A mass media campaign to promote smartphone apps for physical activity is unlikely to generate much health gain or be cost-effective at the population level. Other investments to promote physical activity, particularly those that result in sustained behavior change, are likely to have greater health impacts.

(JMIR Mhealth Uhealth 2020;8(6):e18014) doi: $10.2196 / 18014$

\section{KEYWORDS}

physical activity; mHealth; mobile health; smartphone apps; modeling; mass media campaigns

\section{Introduction}

Insufficient physical activity is associated with an increased risk of cardiovascular diseases, cancers, and poor mental health
[1-3]. International recommendations state that adults should aim to accumulate at least 150 minutes of moderate-to-vigorous physical activity (MVPA) throughout the week [1,4]. Prevalence of insufficient physical activity is high in many countries: $40 \%$ 
in the United States, 34\% in India, 47\% in Brazil, and $42 \%$ in New Zealand [5]. Strategies to increase physical activity at the population level are needed, and the promotion of smartphone apps for physical activity is one promising avenue for intervention.

The rise of physical activity smartphone apps provides an opportunity to deliver interventions that have wide reach and a range of technology-enhanced features (eg, accelerometers, tailored feedback, and reminders) [6]. Evaluations of the effectiveness of physical activity apps have shown they can be effective at increasing physical activity levels [7-9]. However, there is high variability in the quality and effectiveness of the thousands of physical activity apps that are currently available $[6,10]$. Encouraging the use of high-quality apps provides a potential opportunity to increase population-level physical activity owing to the large potential reach and low cost of apps. Additionally, there is growing evidence of the cost-effectiveness of mobile health interventions as a whole [11].

Recent attempts have been made to improve public awareness around the quality and effectiveness of different health apps. Several government agencies around the world now provide app ratings or recommendations on their websites [12-16], but the levels of public engagement have not been publicly documented. Mass media campaigns provide a potential avenue to promote the use of high-quality physical activity apps and, thereby, result in increases in physical activity levels. A recent review suggests that mass media campaigns can be effective, but evidence on the cost-effectiveness is largely limited to tobacco control [17]. Our previous research has assessed the potential of mass media campaigns that promote smartphone apps: a mass media campaign promoting smoking cessation apps is likely to be cost-saving [18], while a mass media campaign for weight loss apps may or may not be cost-effective owing to wide uncertainty around intervention impacts [19]. Although the short-term effectiveness of physical activity apps has been assessed [7,8], it is unknown whether promoting physical activity apps through mass media would be effective or cost-effective. Similarly, we do not know how impacts of mass media campaigns to promote physical activity apps may compare to other public health interventions.

To fill this gap, this study assessed the health impacts, costs, and cost-effectiveness of a mass media campaign to promote high quality smartphone apps for physical activity in a high-income country setting (New Zealand) using a multistate life table modeling approach parameterized with age, sex, and ethnicity specific data consistent with previous work $[18,19]$.

\section{Methods}

\section{Overview}

We used an established proportional multistate life table model to estimate the health impact of a mass media campaign to promote the use of physical activity smartphone apps [20,21]. The model simulates the entire New Zealand population, alive in 2011, out until death under both business-as-usual (BAU) and the modeled intervention. Health gain was measured in quality-adjusted life years (QALYs) - a summary measure of population health that captures both morbidity and mortality impacts to be considered simultaneously [22]. For costs, we used a health-system perspective, and the outputs were the difference in total health system costs (the net sum of intervention costs and downstream cost offsets due to altered disease rates) between BAU and the modeled intervention.

A 3\% discount rate was applied to both health gains and health system costs in accordance with prior New Zealand research. Results for $0 \%$ and $6 \%$ discount rates are presented as scenario analyses. Full details of the model are published elsewhere $[20,21]$.

\section{Intervention Specification}

We modeled a one-off mass media campaign according to the intervention pathway displayed in Figure 1. The population eligible for the intervention included all New Zealand adults 15-79 years of age - the population for which physical activity data were available. Of the population eligible for the intervention, we estimated the proportion of the population that would experience increased physical activity based on likely awareness of the mass media campaign, app download rates, and app use. We defined app use as use for at least 7 days following the initial download of the app to ensure consistency between the modeled intervention pathway and available evidence. Increases in physical activity associated with app use were estimated from a recent systematic review with a meta-analysis of the effectiveness of physical activity apps [8]. Increases in app use wane over time [23], with no evidence of maintained effect beyond 1 year [8]. As our model projects health gains in 1-year time steps, we estimated an average adherence to physical activity apps across the year in which the intervention was implemented [24]. Sources of parameter values are detailed in Table 1, and further detail on parameter selection is available in a related technical report [24]. 
Figure 1. Flow chart of intervention conceptualization. Italicized text represents the percentage of the eligible population exposed to each step in the intervention pathway. NZ: New Zealand.

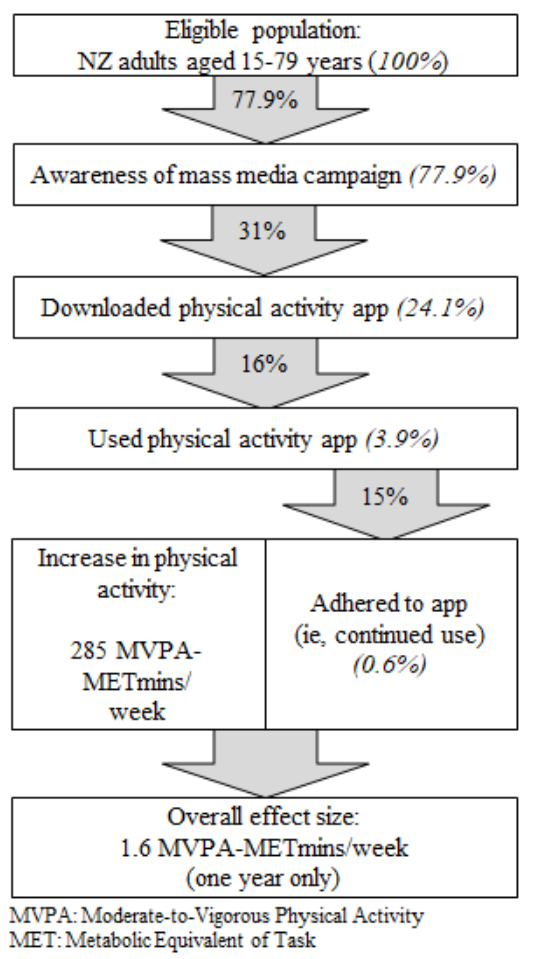

Table 1. Intervention parameters and uncertainty distributions.

\begin{tabular}{|c|c|c|c|}
\hline Parameter & Value & Distribution & Source \\
\hline $\begin{array}{l}\text { Adult } \mathrm{NZ}^{\mathrm{a}} \text { population aware } \\
\text { of mass media campaign, } \% \\
\left(\mathrm{UI}^{\mathrm{b}}\right)\end{array}$ & $77.9(70-83)$ & Beta & $\begin{array}{l}\text { Based on awareness of previous health-related mass media cam- } \\
\text { paign in NZ (Health Promotion Agency [25]) }\end{array}$ \\
\hline $\begin{array}{l}\text { Adult NZ population who } \\
\text { downloaded a physical activi- } \\
\text { ty app, } \% \text { (UI) }\end{array}$ & $31(21-41)$ & Beta & $\begin{array}{l}\text { Estimated based on the proportion of survey respondents who had } \\
\text { downloaded a physical activity app to track behavior (Krebs and } \\
\text { Duncan [26]) }\end{array}$ \\
\hline $\begin{array}{l}\text { Adult NZ population who } \\
\text { used the physical activity app, } \\
\% \text { (UI) }\end{array}$ & $16(10-36)$ & Beta & $\begin{array}{l}\text { Based on the proportion of people likely to "take action" after a } \\
\text { UK-based mass-media campaign to promote app use (Brannan et } \\
\text { al, [13]) }\end{array}$ \\
\hline $\begin{array}{l}\text { Users who adhered to physi- } \\
\text { cal activity app (weighted an- } \\
\text { nual average), \% (UI) }\end{array}$ & $15(10-21)$ & Beta & $\begin{array}{l}\text { Weighted average of estimates of "app only" adherence from } \\
\text { Guertler et al [23] }\end{array}$ \\
\hline \multirow{2}{*}{$\begin{array}{l}\text { Intervention increase in phys- } \\
\text { ical activity for those who ad- } \\
\text { hered to the app (mins/week), } \\
\text { n (SD) }\end{array}$} & \multirow[t]{2}{*}{$285(43)$} & \multirow[t]{2}{*}{ Normal } & $\begin{array}{l}\text { Reported increase of } 1404 \text { steps per day from recent meta-analysis } \\
\text { of randomized controlled trials (Gal et al [8]) was converted to }\end{array}$ \\
\hline & & & $\begin{array}{l}\text { MVPA }^{\mathrm{c}} \text {-MET }{ }^{\mathrm{d}} \text { mins/week, assuming a conversion factor of } 34.5 \\
\text { steps equating to } 1 \mathrm{MVPA}-\mathrm{MET} \min [24]\end{array}$ \\
\hline $\begin{array}{l}\text { Cost of a one-off national } \\
\text { level mass media campaign } \\
(\mathrm{NZ} \$), \mathrm{n}(\mathrm{SD} \%)\end{array}$ & $2,883,000(20)$ & Gamma & $\begin{array}{l}\text { As per a similar NZ study for promoting a weight loss app, by } \\
\text { Cleghorn et al [19]; includes costs associated with identification } \\
\text { of high-quality apps and mass media campaign across multiple } \\
\text { media }\end{array}$ \\
\hline
\end{tabular}

${ }^{\mathrm{a}} \mathrm{NZ}$ : New Zealand.

${ }^{\mathrm{b}} \mathrm{UI}$ : uncertainty interval.

${ }^{c}$ MVPA: moderate-to-vigorous physical activity.

${ }^{\mathrm{d}}$ MET: metabolic equivalent of task.

The total cost of the intervention was estimated at NZ $\$ 2,883,000$ (using consumer price index and purchasing power parity adjustments, the currency exchange rate used for this paper was $2011 \mathrm{NZ} \$ 1=2018$ US \$0.73) from a previous NZ study of the costs associated with a modeled mass media campaign to promote a weight loss app [19]. The cost of the intervention captured the costs associated with identifying the highest quality apps, promotion of the highest quality apps for 
physical activity on relevant government websites, and a mass media campaign rolled out across multiple media. These costs were also similar to the estimated cost for a modeled mass media campaign to promote smoking cessation apps [18].

Increases in physical activity were applied to the proportion of the population who downloaded and used the app for at least 7 days. We assumed that the intervention effect would apply to adults 15-79 years of age. This was the population range covered in studies included in the review used to estimate physical activity increases in response to physical activity apps [8].

For those who used the app for at least 7 days, we estimated that physical activity would increase by an average of 285 moderate-to-vigorous physical activity-metabolic equivalent of task (MET) mins/week using a recent meta-analysis examining increases in physical activity associated with app use [8]. This is equivalent to 1.6 hours of additional brisk walking per week. We assumed that the intervention increase in physical activity would wane over the course of the year in which the intervention was implemented, with no effect beyond the first year of the intervention. This was in line with the source of our estimate of intervention increase in physical activity, where included studies were evaluated based on the short-term ( $<3$ months) impacts.

BAU was assumed to include the existing levels of physical activity and existing levels of physical activity app use, with no additional promotion. The current promotion of physical activity apps in New Zealand was considered negligible, and therefore, the BAU physical activity distribution was assumed to reflect the continuation of a low or no physical activity app promotion environment.

\section{Multistate Life Table Model}

The model consists of a main life table parameterized with age, sex, and ethnicity (Māori-the indigenous population of New Zealand-and non-Māori) specific all-cause mortality and morbidity rates. Alongside the main life table are 9 parallel physical activity and transport-related disease life tables where proportions of the population simultaneously reside: coronary heart disease (CHD), stroke, type 2 diabetes, colorectal cancer, breast cancer (females only), chronic obstructive pulmonary disease (COPD), lower respiratory tract infection (LRTI), lung cancer, and road transport injury. Modeled diseases include both physical activity and transport-related conditions, as the model was designed to examine both interventions. COPD, LRTI, lung cancer, and road transport injury were inactive (ie, "turned off") in this study, as they are not associated with physical activity (see Figure 2 for the conceptual diagram, adapted from Mizdrak et al [20]). The proportions of the population in each disease life table at each annual time step are a function of past and current disease incidence, case fatality, and remission (for cancers only) rates.

Figure 2. Conceptual diagram of model. CHD: coronary heart disease; COPD: chronic obstructive pulmonary disease; LRTI: lower respiratory tract infection.

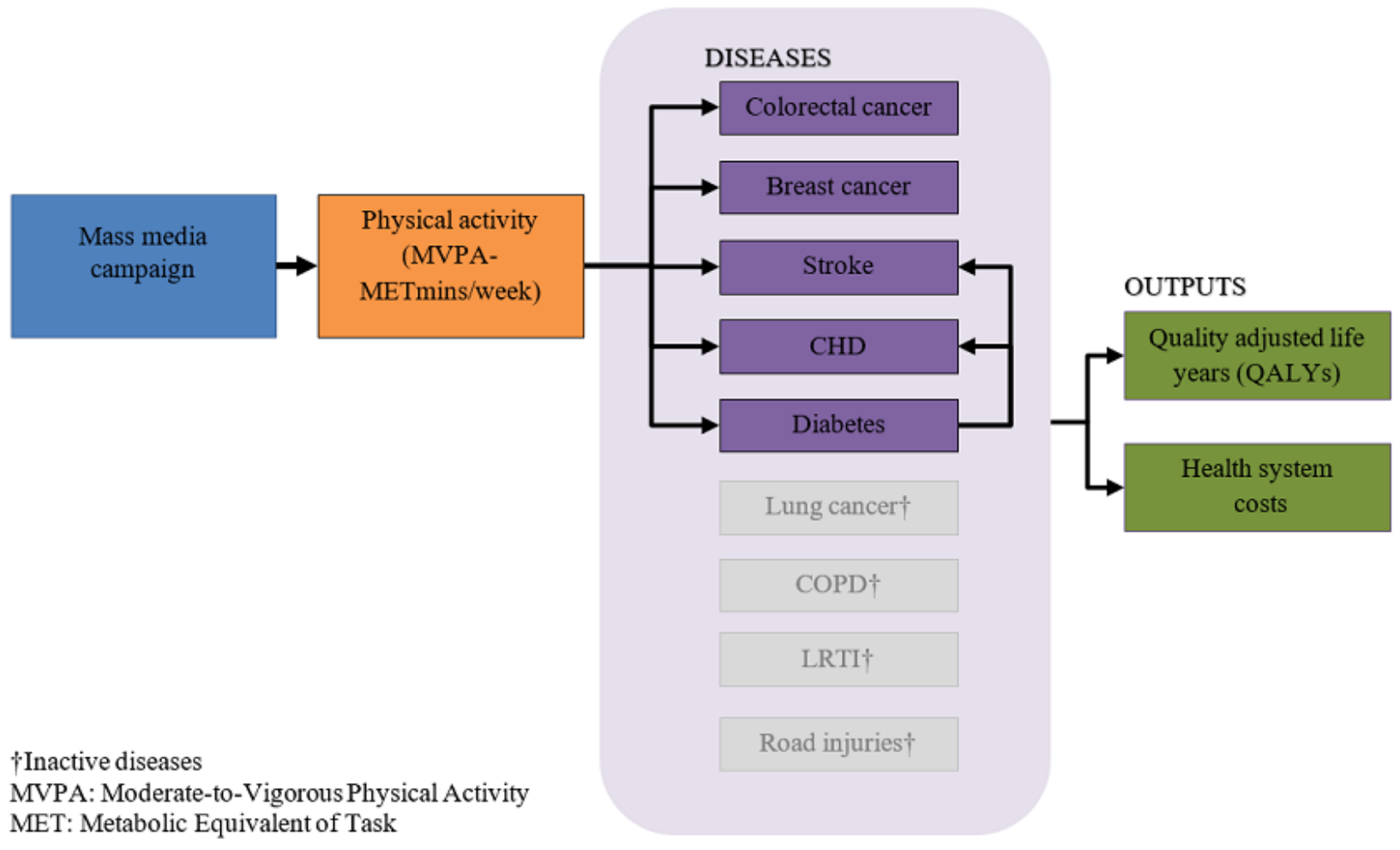

The physical activity distribution of the New Zealand adult population was estimated by converting responses to the New Zealand Physical Activity Questionnaire Short Form in the New Zealand Health Survey to MET minutes per week of moderate and vigorous physical activity. A MET is the ratio of work metabolic rate to a standard resting metabolic rate, where 1 MET is equivalent to quiet sitting [27]. Brisk walking was assigned a MET value of 3.0, moderate activities a MET value of 4.5, and vigorous activities a MET value of 6.5 [20]. 
The modeled intervention induced changes in physical activity were combined with relative risks for the association between physical activity and disease outcomes (CHD, stroke, type 2 diabetes, breast cancer, colorectal cancer) to produce population impact fractions [28]. These were used in the model to modify incidence rates of diseases, which in turn results in changes in all-cause mortality and morbidity rates. The model includes time lags to account for the nonimmediate impact of changes in population risk distribution on disease incidence: changes in CHD, stroke, and type 2 diabetes are based on the average population impact fraction over the past 0-5 years, for cancers on average for the previous 10-30 years [20]. For modeling parsimony, we assumed that there would be no impact of the modeled intervention on health beyond that captured through the diseases previously mentioned, including no impact on obesity, injury, or mental health outcomes. These assumptions are consistent with the evidence base: there does not appear to be a consistent association with weight loss for apps that specifically target physical activity [29], and there is no evidence (to our knowledge) of the impact of physical activity apps on mental health outcomes or injury (as covered further in the Discussion).

In addition, the model captures changes in health system costs associated with changing disease prevalence and population longevity. Disease-specific costs were based on the timing of events (first year, subsequent year, and last 6 months of life) and were derived according to an established protocol [30]. Changes in the proportion of the population in each disease state result in proportional changes in health system costs, and the model captures unrelated health system costs (ie, increases in health system costs out into the future due to people living longer as a result of the modeled intervention).

Our results project the health gains and health system cost impacts for the remainder of the life course of the modeled population. Both health gains and health system costs were discounted at $3 \%$, with key results using $0 \%$ and $6 \%$ discount rates presented as sensitivity analyses. We also ran the results applying an "equity adjustment" that set background mortality and morbidity rates for Māori to non-Māori values, a routinely used modeling technique that avoids undervaluation of health gains for disadvantaged populations [31]. Scenario analyses included a scenario where the age range for the intervention was restricted to those 40-79 years of age with total intervention costs remaining the same, and one in which we assumed that the intervention impact would be maintained for 5 years following the intervention. Finally, tornado plots show the contribution of assumptions around each step in the intervention pathway to model uncertainty of the results.

The model was built in Microsoft Excel (Microsoft Corporation) and run using a macro written in Visual Basic for Applications. Uncertainty around health gains and cost-effectiveness was estimated using a Monte Carlo analysis; the model was run 2000 times with parameters sampled independently from their respective probability distributions. Results are given as the 50th percentile of all model runs, with 2.5 th and 97.5 th percentiles representing the $95 \%$ uncertainty interval (UI) around modeled values. The probability of cost-effectiveness at different monetary thresholds was based on the proportion of model runs with an incremental cost-effectiveness ratio (ICER) below the threshold. Further model details are provided in a technical report [20].

\section{Results}

The one-off mass media campaign promoting smartphone apps for physical activity resulted in an increase of 28 QALYs $(95 \%$ UI 8-72) over the lifetime of the 2011 population, or 0.008 QALYs gained per 1000 people (see Table 2). The modeled improvements in health came at a net cost of NZ \$2.2 million (US \$1,625,000; 95\% UI 1.02 million-3.5 million). The ICER was NZ \$81,000 (US \$59,000; 95\% UI 17,000-345,000) per QALY gained. The intervention had a low probability (20\%) of being cost-effective at a cost-effectiveness threshold of NZ $\$ 45,000$ per QALY gained (see Figure 3).

Health gains per capita were higher in older age groups, and, assuming the intervention costs were spread evenly across the eligible population, the intervention was more likely to be cost-effective in older age groups compared to younger age groups (ie, more likely to be under the NZ $\$ 45,000$ threshold). Health gains for Māori increased with the application of the "equity adjustment" (ie, non-Māori mortality and morbidity rates used for Māori; see Table 3). 
Table 2. Health gains and cost-effectiveness of a mass media campaign to promote physical activity smartphone apps by age, sex, and ethnicity (lifetime gains, $3 \%$ discount rate).

\begin{tabular}{|c|c|c|c|}
\hline Sex, ethnicity & Age group (years) & QALYs ${ }^{\mathrm{a}} / 1000$ population $\left(\mathrm{UI}^{\mathrm{b}}\right)$ & Cost per QALY gained: ICER ${ }^{\mathrm{c}}, 2011 \mathrm{NZ}$ \$(UI) \\
\hline All, all & All groups & $0.008(0.002-0.021)$ & $81,000(17,000-345,000)$ \\
\hline \multicolumn{4}{|l|}{ Male } \\
\hline \multicolumn{4}{|c|}{ Non-Māori } \\
\hline & $<40$ & $0.001(0.000-0.003)$ & $606,000(190,000-2,368,000)$ \\
\hline & $40-60$ & $0.008(0.002-0.021)$ & $86,000(16,000-384,000)$ \\
\hline & $60-80$ & $0.021(0.006-0.055)$ & 27,000 (cost-saving ${ }^{\mathrm{d}}$ to 147,000$)$ \\
\hline \multicolumn{4}{|l|}{ Māori } \\
\hline & $<40$ & $0.002(0.001-0.006)$ & $354,000(111,000-1,384,000)$ \\
\hline & $40-60$ & $0.018(0.005-0.047)$ & $35,000(2000-179,000)$ \\
\hline & $60-80$ & $0.031(0.009-0.083)$ & 16,000 (cost-saving to 96,000 ) \\
\hline \multicolumn{4}{|l|}{ Female } \\
\hline \multicolumn{4}{|c|}{ Non-Māori } \\
\hline & $<40$ & $0.002(0.000-0.005)$ & $393,000(120,000-1,499,000)$ \\
\hline & $40-60$ & $0.006(0.002-0.017)$ & $119,000(26,000-495,000)$ \\
\hline & $60-80$ & $0.023(0.007-0.061)$ & 26,000 (cost-saving to 132,000 ) \\
\hline \multicolumn{4}{|l|}{ Māori } \\
\hline & $<40$ & $0.003(0.001-0.009)$ & $196,000(54,000-768,000)$ \\
\hline & $40-60$ & $0.019(0.005-0.049)$ & $31,000(0-158,000)$ \\
\hline & $60-80$ & $0.035(0.010-0.094)$ & $15,000$ (cost-saving to 87,000$)$ \\
\hline
\end{tabular}

${ }^{a}$ QALY: quality-adjusted life year.

${ }^{\mathrm{b}} \mathrm{UI}$ : uncertainty interval.

${ }^{\mathrm{c}}$ ICER: incremental cost-effectiveness ratio.

${ }^{d}$ Negative cost per QALY gained (ie, the intervention results in cost-savings to the health system).

Figure 3. Probability of the modeled physical activity app promotion intervention being cost-effective for different cost-effectiveness thresholds (in cost per quality-adjusted life year gained).

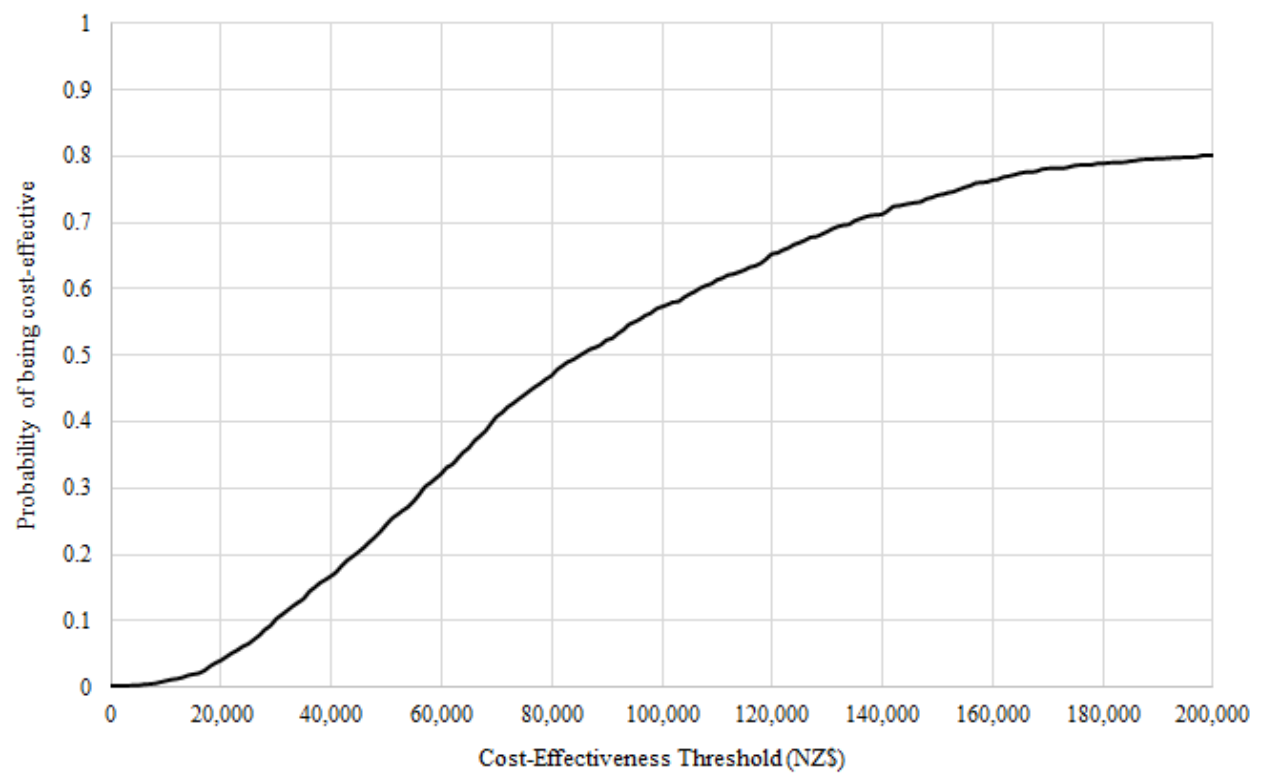


Table 3. Results for Māori (Indigenous population) with equity adjustment applied (lifetime gains, 3\% discount rate).

\begin{tabular}{lll}
\hline Sex, age (years) & QALYs ${ }^{\mathrm{a}} / 1000$ people $\left(\mathrm{UI}^{\mathrm{b}}\right)$ & Cost per QALY gained: ICER $^{\mathrm{c}}, 2011 \mathrm{NZ} \$(\mathrm{UI})$ \\
\hline Male & $0.002(0.001-0.006)$ & $315,000(92,000-1,191,000)$ \\
$<40$ & $0.022(0.006-0.058)$ & $30,000(1000-142,000)$ \\
$40-60$ & $0.046(0.012-0.126)$ & $11,000\left(\right.$ cost-saving ${ }^{\mathrm{d}}$ to 69,000$)$ \\
$60-80$ & & \\
Female & $0.004(0.001-0.010)$ & $172,000(43,000-669,000)$ \\
$<40$ & $0.024(0.006-0.062)$ & $26,000($ cost-saving to 130,000$)$ \\
$40-60$ & $0.052(0.014-0.137)$ & $10,000($ cost-saving to 64,000) \\
$60-80$ &
\end{tabular}

${ }^{\mathrm{a} Q A L Y: ~ q u a l i t y-a d j u s t e d ~ l i f e ~ y e a r . ~}$

bUI: uncertainty interval.

${ }^{\mathrm{c}}$ ICER: incremental cost-effectiveness ratio.

${ }^{\mathrm{d}}$ Negative cost per QALY gained (ie, the intervention results in cost-savings to the health system).

We explored the impact of selected changes to model the discount rate had the expected impact on the overall results, specification on the results (see Table 4). Given that the with a zero-discount rate resulting in higher health gains. intervention was least cost-effective in the youngest age group, we ran a scenario analysis to determine the extent that the overall cost-effectiveness might be improved by narrowing the population targeted by the intervention to those $40-80$ years of age. This slightly increased the average cost-effectiveness of the intervention. Assuming the impact of the intervention held for 5 years rather than 1 year, the health gains would be over four times larger than in the main analysis and would result in much lower health system costs, resulting in a highly cost-effective ICER of NZ \$2000 per QALY gained. Changing

Finally, we examined the contribution of different intervention parameters to uncertainty in the modeled results. Uncertainty in health gains was driven by uncertainty in the app use parameter, and uncertainty in health system cost impacts was driven by uncertainty in the intervention cost parameter (see Figures S1 and S2 in Multimedia Appendix 1). The picture for the ICER was less clear; uncertainty in app use was the greatest contributor to uncertainty in the ICER, but this was closely followed by uncertainty around other intervention parameters (see Figure 4).

Table 4. Sensitivity and scenario analyses for a one-off national-level mass media campaign to promote smartphone apps for physical activity (expected value analysis, lifetime perspective, $3 \%$ discount rate, unless otherwise stated).

\begin{tabular}{|c|c|c|c|}
\hline Sensitivity/scenario analyses ${ }^{a}$ & $\begin{array}{l}\text { Health gain } \\
\left(\text { QALYs }^{\mathrm{b}}\right)\end{array}$ & Net health system costs (NZ \$) & $\begin{array}{l}\text { Cost per QALY gained: } \\
\operatorname{ICER}^{\mathrm{b}}(\mathrm{NZ} \$)\end{array}$ \\
\hline Base case analysis & 33 & $2,315,000$ & 81,000 \\
\hline $\begin{array}{l}\text { Target age range set to } 40-80 \text { years of age (otherwise base } \\
\text { case) }\end{array}$ & 30 & $2,387,000$ & 80,000 \\
\hline $\begin{array}{l}\text { 5-year maintenance of additional physical activity levels } \\
\text { followed by a return to preintervention levels (otherwise } \\
\text { base case) }\end{array}$ & 126 & 241,146 & 2000 \\
\hline $0 \%$ discount rate & 57 & $2,153,000$ & 38,000 \\
\hline $6 \%$ discount rate & 22 & $2,332,000$ & 108,000 \\
\hline
\end{tabular}

${ }^{\mathrm{a}}$ Expected values given for all scenarios.

${ }^{b}$ QALY: quality-adjusted life year.

${ }^{c}$ ICER: incremental cost-effectiveness ratio. 
Figure 4. Tornado plot showing the contribution of parameter uncertainty to overall uncertainty in the incremental cost-effectiveness ratio for the whole adult population.

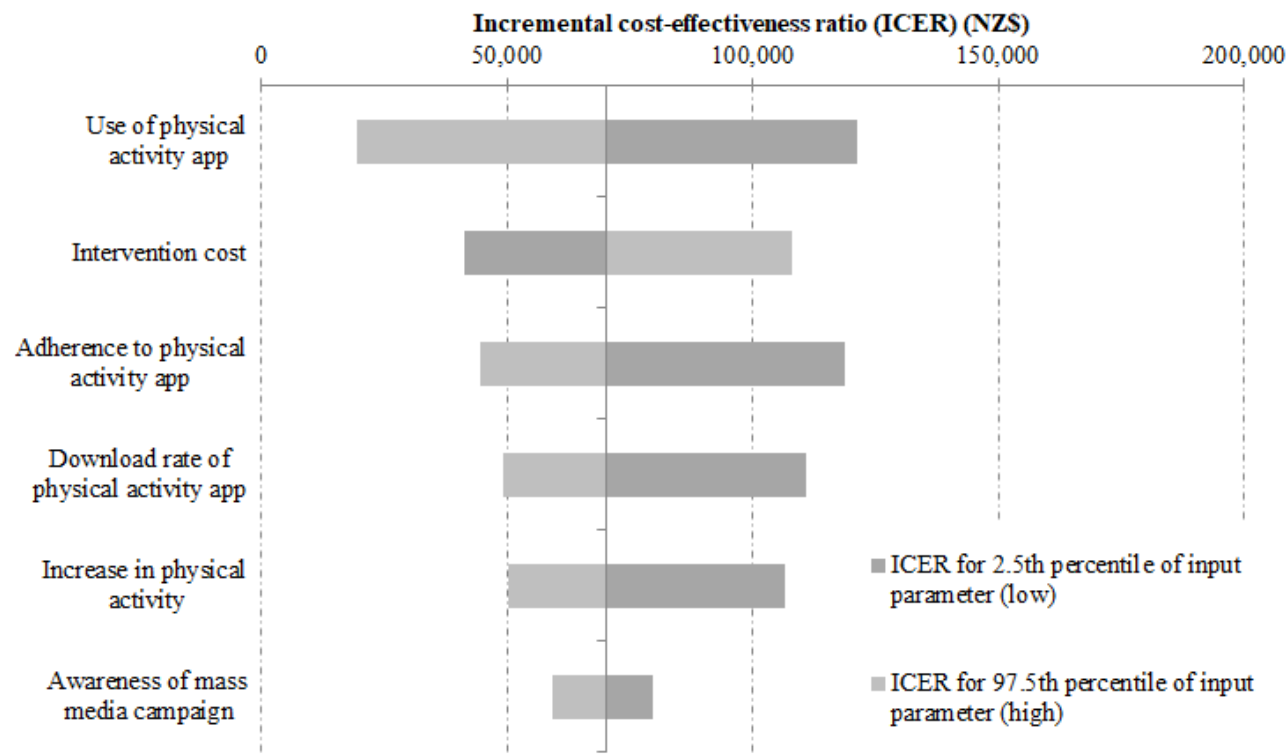

\section{Discussion}

\section{Principal Findings}

We modeled the likely impact of a one-off national-level mass media campaign to promote uptake of smartphone apps for physical activity using published estimates of uptake, adherence, and effectiveness $[8,13,23,25,26]$. Modeled through changes in disease incidence the intervention has a $20 \%$ chance of being cost-effective for the whole target population at a commonly applied threshold of GDP per capita of the country (ie, NZ $\$ 45,000$ per QALY gained for New Zealand) [32]. There was also wide uncertainty around the health system cost impacts and cost-effectiveness of the intervention.

\section{Comparison With Prior Work}

This is the first study of the cost-effectiveness of mass media promotion of smartphone apps for physical activity, at least that we are aware of. This study contributes to calls to build the evidence base on the cost-effectiveness of physical activity interventions [33]. This work also has a high level of comparability with previous research on other health-related app promotion in the NZ setting. We found that a mass media campaign to promote physical activity apps appears to be less effective in achieving health gain and less cost-effective than mass media campaigns to promote smoking cessation (modeled impact: 6760 QALYs, NZ \$115 million savings to the health system [18]) but was similar to a campaign to promote the use of weight loss apps (modeled impact: 29 QALYs, ICER of NZ $\$ 79,700$ [19]). This suggests that mass media campaigns to promote apps may have different impacts depending on the behavior targeted by apps.

Our results also indicate lower effectiveness and poorer cost-effectiveness on a per capita basis than previous research that modeled the effectiveness of a mass media campaign and other strategies to promote physical activity in Australia [34]. This is likely due to our study applying more conservative estimates for the impact of a mass media campaign intervention than earlier work and differences in underlying physical activity patterns and epidemiology across different countries.

\section{Strengths and Limitations}

This study has the strength of using an established multistate life table model based on rich disease-specific epidemiological and costing data. Multistate life table modeling captures health impacts across multiple diseases over time. The widespread use of this modeling methodology across Australasia means we are able to compare our results to those of other health interventions (eg, $[18,19,34])$. Limitations of multistate life table modeling include the assumption of disease independence and our use of a health-system perspective for costs and benefits. Regarding the former, we do account for the relationship between type 2 diabetes and CHD and stroke, given that type 2 diabetes is a risk factor for these conditions. The health system perspective of this study means that potential costs and benefits outside the health system (eg, the cost of the original development of physical activity apps) were not captured. However, our methods could be adapted to include additional costs and benefits for different audiences. For example, we are currently exploring the inclusion of productivity impacts, such as income loss from disease diagnosis, into our models.

Effect sizes were based on a review of relevant sources that were then assessed on both methodological rigor and appropriateness for modeling (see Multimedia Appendix 1 for further details). We also were able to model parameter uncertainty around all the key parameters and a range of sensitivity and scenario analyses.

We presented heterogeneity in the health impacts of the modeling intervention. As we assumed no heterogeneity in intervention impact, our estimates reflected differential health gains owing to underlying differences in physical activity levels and epidemiology, and not differential response to the intervention. There was insufficient information in the sources of parameter estimates to suggest differences in intervention impacts by age, sex, or ethnicity. Previous research has shown 
high levels of engagement with physical activity apps across subpopulations, including older adults [35] and different ethnic groups [36]. However, if certain population groups are more or less likely to respond to the intervention, then this would influence the overall effectiveness and cost-effectiveness. Future evaluations of physical activity app interventions should explicitly consider differential impacts in intervention uptake and efficacy, especially given that our results showed differences in the health gain likely to be achieved.

We assumed that any impact of the intervention on physical activity levels would be restricted to the year in which the intervention was implemented, consistent with existing evidence. The majority of physical activity apps have only been evaluated for short-term ( $<3$ months) impact [7,8]. Our estimate of average adherence in the year that the app was implemented is consistent with the small number of studies that have evaluated physical activity impacts beyond 3 months [23,37]. There was no evidence to support modeling an intervention impact that extended beyond 1 year, and this highlights the need for longer-term evaluations of physical activity app interventions, especially as our scenario analysis demonstrates that considerably larger health gains could be achieved if intervention impacts were maintained over time. Evidence of long-term impacts on physical activity have been observed with interventions to improvement in walking and cycling infrastructure [38,39], suggesting that structural interventions that change environments may be more effective than interventions targeting individual-level behavior change in an unsupportive environment.

The model captures health impacts through the conditions that are strongly associated with MVPA including cardiovascular diseases, type 2 diabetes, and selected cancers. We did not capture potential additional health gains or losses from obesity, mental health, or injury. Although apps have been shown to be effective in promoting weight loss [40], effect sizes predominantly capture apps designed to influence both physical activity and dietary behaviors. For apps that specifically target physical activity, there does not appear to be a consistent association with weight loss [29]. In addition, the impact of physical activity apps on mental health outcomes has not been quantified (to our knowledge). Although regular physical activity is associated with improved mental health [41], recent evidence suggests that a high percentage of fitness apps contain features linked to negative body image and maladaptive exercise behavior [42]. Further research is needed to understand whether health gains associated with increased physical activity through app use are complemented or counteracted by other health-related outcomes, including weight loss, injury, and mental health.

\section{Policy Implications}

The wide UIs around our modeled results demonstrate the need for better evaluations of app-based and other physical activity interventions. In particular, we need to better understand what interventions are most likely to result in long-term maintenance of physical activity increases, as these are the interventions that will result in the largest health gains. Modeling studies such as this one are a valuable approach to quantify the health gains that may be possible with different intervention options prior to implementing specific interventions.

Although physical activity apps offer the potential to increase physical activity at the individual level, our results suggest that promoting physical activity apps through mass media is currently unlikely to be an effective or cost-effective public health intervention at the population level, at least with existing app designs and mass media campaign methods. Cost-effectiveness of a mass media campaign to promote smartphone apps for physical activity could be improved by delivering more targeted campaigns using social media; this may deliver health gains at lower cost than the intervention modeled here. Worldwide, there is recognition that targeted, individual-focused interventions need to be combined strategically with policy actions that support physical activity [41]. Our results suggest that a mass media campaign to promote smartphone apps for physical activity is not cost-effective as a stand-alone intervention. Other strategies to promote physical activity that result in long-term behavior change are likely to be more effective (eg, investment in walking and cycling infrastructure [38]). Our results are likely to be generalizable to similar contexts-high-income countries with similar epidemiology, physical activity levels, app uptake, and other population characteristics.

\section{Conclusion}

A one-off national-level mass media campaign to promote the use of smartphone apps for physical activity is unlikely to generate much health gain. Based on current and often weak evidence, it also appears unlikely to be cost-effective at the population level. Investments in physical activity that are associated with long-term maintenance of behavior are likely to be of greater benefit.

\section{Acknowledgments}

The authors gratefully acknowledge the Health Research Council of New Zealand (HRC16/443) for providing the funding for this study.

\section{Conflicts of Interest}

None declared.

\section{Multimedia Appendix 1}

Supplementary materials. 


\section{References}

1. World Health Organization. Global recommendations on physical activity for health. World Health Organization 2010.

2. Wahid A, Manek N, Nichols M, Kelly P, Foster C, Webster P, et al. Quantifying the association between physical activity and cardiovascular disease and diabetes: a systematic review and meta-analysis. J Am Heart Assoc 2016 Sep 14;5(9) [FREE Full text] [doi: 10.1161/JAHA.115.002495] [Medline: 27628572]

3. Kyu HH, Bachman VF, Alexander LT, Mumford JE, Afshin A, Estep K, et al. Physical activity and risk of breast cancer, colon cancer, diabetes, ischemic heart disease, and ischemic stroke events: systematic review and dose-response meta-analysis for the Global Burden of Disease Study 2013. BMJ 2016 Aug 09;354:i3857 [FREE Full text] [doi: 10.1136/bmj.i3857] [Medline: 27510511]

4. Piercy KL, Troiano RP, Ballard RM, Carlson SA, Fulton JE, Galuska DA, et al. The physical activity guidelines for Americans. JAMA 2018 Nov 20;320(19):2020-2028. [doi: 10.1001/jama.2018.14854] [Medline: 30418471]

5. World Health Organization. 2018. Global Health Observatory Data Repository: prevalence of insufficient physical activity among adults URL: http://apps.who.int/gho/data/view.main.2463?lang=en

6. Bondaronek P, Alkhaldi G, Slee A, Hamilton FL, Murray E. Quality of publicly available physical activity apps: review and content analysis. JMIR Mhealth Uhealth 2018 Mar 21;6(3):e53 [FREE Full text] [doi: 10.2196/mhealth.9069] [Medline: 29563080]

7. Romeo A, Edney S, Plotnikoff R, Curtis R, Ryan J, Sanders I, et al. Can smartphone apps increase physical activity? Systematic review and meta-analysis. J Med Internet Res 2019 Mar 19;21(3):e12053 [FREE Full text] [doi: 10.2196/12053] [Medline: 30888321]

8. Gal R, May AM, van Overmeeren EJ, Simons M, Monninkhof EM. The effect of physical activity interventions comprising wearables and smartphone applications on physical activity: a systematic review and meta-analysis. Sports Med Open 2018 Sep 03;4(1):42 [FREE Full text] [doi: 10.1186/s40798-018-0157-9] [Medline: 30178072]

9. Feter N, Dos Santos TS, Caputo EL, da Silva MC. What is the role of smartphones on physical activity promotion? A systematic review and meta-analysis. Int J Public Health 2019 Jun;64(5):679-690. [doi: 10.1007/s00038-019-01210-7] [Medline: 30758514]

10. Direito A, Dale LP, Shields E, Dobson R, Whittaker R, Maddison R. Do physical activity and dietary smartphone applications incorporate evidence-based behaviour change techniques? BMC Public Health 2014 Jun 25;14:646 [FREE Full text] [doi: 10.1186/1471-2458-14-646] [Medline: 24965805]

11. Iribarren SJ, Cato K, Falzon L, Stone PW. What is the economic evidence for mHealth? A systematic review of economic evaluations of mHealth solutions. PLoS One 2017;12(2):e0170581 [FREE Full text] [doi: 10.1371/journal.pone.0170581] [Medline: 28152012]

12. National Health Service. 2016. NHS Apps Library URL: https://www.nhs.uk/conditions/nhs-health-check/ tools-and-technology-that-can-help/ [accessed 2020-05-26]

13. Brannan M, Foster C, Timpson C, Clarke N, Sunyer E, Amlani A, et al. Active 10 - a new approach to increase physical activity in inactive people in England. Prog Cardiovasc Dis 2019;62(2):135-139. [doi: 10.1016/j.pcad.2019.02.001] [Medline: $\underline{30796943]}$

14. National Health Service. 2017. NHS Diabetes Prevention Programme - digital stream URL: https://www.england.nhs.uk/ diabetes/digital-innovations-to-support-diabetes-outcomes/nhs-diabetes-prevention-programme-digital-stream/

15. Australian Government Department of Health. 2018. Mobile apps URL: https://campaigns.health.gov.au/girlsmove/ mobile-apps [accessed 2020-05-26]

16. Health Navigator New Zealand. 2019. About the Health Navigator app library URL: https://www.healthnavigator.org.nz/ apps/p/people-process/ [accessed 2020-05-26]

17. Stead M, Angus K, Langley T, Katikireddi S, Hinds K, Hilton S, et al. Mass media to communicate public health messages in six health topic areas: a systematic review and other reviews of the evidence. Public Health Research 2019;7(6):a. [doi: 10.3310/phr07080] [Medline: 31046212]

18. Nghiem N, Leung W, Cleghorn C, Blakely T, Wilson N. Mass media promotion of a smartphone smoking cessation app: modelled health and cost-saving impacts. BMC Public Health 2019 Mar 08;19(1):283 [FREE Full text] [doi: 10.1186/s12889-019-6605-8] [Medline: 30849943]

19. Cleghorn C, Wilson N, Nair N, Kvizhinadze G, Nghiem N, McLeod M, et al. Health benefits and cost-effectiveness from promoting smartphone apps for weight loss: multistate life table modeling. JMIR Mhealth Uhealth 2019 Jan 15;7(1):e11118 [FREE Full text] [doi: 10.2196/11118] [Medline: 30664471]

20. Mizdrak A, Blakely T, Cleghorn C, Cobiac L. Technical report for BODE3 active transport and physical activity model. Department of Public Health, University of Otago, Wellington Technical Report No 2018:18.

21. Mizdrak A, Blakely T, Cleghorn CL, Cobiac LJ. Potential of active transport to improve health, reduce healthcare costs, and reduce greenhouse gas emissions: A modelling study. PLoS One 2019;14(7):e0219316 [FREE Full text] [doi: 10.1371/journal.pone.0219316] [Medline: $\underline{\text { 31314767] }}$ 
22. Gold MR, Stevenson D, Fryback DG. HALYS and QALYS and DALYS, Oh My: similarities and differences in summary measures of population Health. Annu Rev Public Health 2002;23:115-134. [doi: 10.1146/annurev.publhealth.23.100901.140513] [Medline: 11910057 ]

23. Guertler D, Vandelanotte C, Kirwan M, Duncan MJ. Engagement and nonusage attrition with a free physical activity promotion program: the case of 10,000 steps Australia. J Med Internet Res 2015 Jul 15;17(7):e176 [FREE Full text] [doi: 10.2196/jmir.4339] [Medline: 26180040]

24. Telfer K, Wilson N, Direito A, Mizdrak A. Technical report for BODE3 intervention parameter selection: mobile health for physical activity. Technical Report No. 38. Wellington, New Zealand 2020:2020.

25. Health Promotion Agency. Health Promotion Agency annual report for the year ended 30 June 2014. Health Promotion Agency 2014.

26. Krebs P, Duncan DT. Health app use among US mobile phone owners: a national survey. JMIR Mhealth Uhealth 2015 Nov 04;3(4):e101 [FREE Full text] [doi: 10.2196/mhealth.4924] [Medline: 26537656]

27. Ainsworth BE, Haskell WL, Herrmann SD, Meckes N, Bassett DR, Tudor-Locke C, et al. 2011 Compendium of Physical Activities: a second update of codes and MET values. Med Sci Sports Exerc 2011 Aug;43(8):1575-1581. [doi: 10.1249/MSS.0b013e31821ece12] [Medline: 21681120]

28. Murray CJ, Ezzati M, Lopez AD, Rodgers A, Vander Hoorn S. Comparative quantification of health risks conceptual framework and methodological issues. Popul Health Metr 2003 Apr 14;1(1):1 [FREE Full text] [doi: 10.1186/1478-7954-1-1] [Medline: $\underline{12780936}$ ]

29. Schoeppe S, Alley S, Van Lippevelde W, Bray NA, Williams SL, Duncan MJ, et al. Efficacy of interventions that use apps to improve diet, physical activity and sedentary behaviour: a systematic review. Int J Behav Nutr Phys Act 2016 Dec 07;13(1):127 [FREE Full text] [doi: 10.1186/s12966-016-0454-y] [Medline: 27927218]

30. Kvizhinadze G, Nghiem N, Atkinson J, Blakely T. University of Otago Wellington. 2016. Cost off-sets used in BODE3 multistate lifetable models URL: https://www.otago.ac.nz/wellington/otago619391.pdf [accessed 2020-05-26]

31. McLeod M, Blakely T, Kvizhinadze G, Harris R. Why equal treatment is not always equitable: the impact of existing ethnic health inequalities in cost-effectiveness modeling. Popul Health Metr 2014;12:15 [FREE Full text] [doi: 10.1186/1478-7954-12-15] [Medline: 24910540]

32. Kvizhinadze G, Wilson N, Nair N, McLeod M, Blakely T. How much might a society spend on life-saving interventions at different ages while remaining cost-effective? A case study in a country with detailed data. Popul Health Metr 2015;13:15 [FREE Full text] [doi: 10.1186/s12963-015-0052-2] [Medline: 26155199]

33. Love R, Adams J, van Sluijs EMF, Foster C, Humphreys D. A cumulative meta-analysis of the effects of individual physical activity interventions targeting healthy adults. Obes Rev 2018 Aug;19(8):1164-1172 [FREE Full text] [doi: 10.1111/obr.12690] [Medline: 29701299]

34. Cobiac LJ, Vos T, Barendregt JJ. Cost-effectiveness of interventions to promote physical activity: a modelling study. PLoS Med 2009 Jul 14;6(7):e1000110 [FREE Full text] [doi: 10.1371/journal.pmed.1000110] [Medline: 19597537]

35. Shake MC, Crandall KJ, Mathews RP, Falls DG, Dispennette AK. Efficacy of Bingocize: a game-centered mobile application to improve physical and cognitive performance in older adults. Games Health J 2018 Aug;7(4):253-261. [doi: 10.1089/g4h.2017.0139] [Medline: 30089018]

36. Ni Mhurchu C, Te Morenga L, Tupai-Firestone R, Grey J, Jiang Y, Jull A, et al. A co-designed mHealth programme to support healthy lifestyles in Māori and Pasifika peoples in New Zealand (OL@-OR@): a cluster-randomised controlled trial. Lancet Digital Health 2019 Oct;1(6):e298-e307. [doi: 10.1016/s2589-7500(19)30130-x]

37. Hermsen S, Moons J, Kerkhof P, Wiekens C, De Groot M. Determinants for sustained use of an activity tracker: observational study. JMIR Mhealth Uhealth 2017 Oct 30;5(10):e164 [FREE Full text] [doi: 10.2196/mhealth.7311] [Medline: 29084709]

38. Goodman A, Sahlqvist S, Ogilvie D, iConnect Consortium. New walking and cycling routes and increased physical activity: one- and 2-year findings from the UK iConnect Study. Am J Public Health 2014 Sep;104(9):e38-e46. [doi: 10.2105/AJPH.2014.302059] [Medline: 25033133]

39. Smith M, Hosking J, Woodward A, Witten K, MacMillan A, Field A, et al. Systematic literature review of built environment effects on physical activity and active transport - an update and new findings on health equity. Int J Behav Nutr Phys Act 2017 Nov 16;14(1):158 [FREE Full text] [doi: 10.1186/s12966-017-0613-9] [Medline: 29145884]

40. Flores Mateo G, Granado-Font E, Ferré-Grau C, Montaña-Carreras X. Mobile phone apps to promote weight loss and increase physical activity: a systematic review and meta-analysis. J Med Internet Res 2015 Nov 10;17(11):e253 [FREE Full text] [doi: 10.2196/jmir.4836] [Medline: 26554314]

41. World Health Organization. Global action plan on physical activity 2018-2030: more active people for a healthier world. World Health Organization 2018.

42. Honary M, Bell BT, Clinch S, Wild SE, McNaney R. Understanding the role of healthy eating and fitness mobile apps in the formation of maladaptive eating and exercise behaviors in young people. JMIR Mhealth Uhealth 2019 Jun 18;7(6):e14239 [FREE Full text] [doi: 10.2196/14239] [Medline: $\underline{\text { 31215514] }}$ 


\section{Abbreviations}

BAU: business-as-usual

CHD: coronary heart disease

COPD: chronic obstructive pulmonary disease

ICER: incremental cost-effectiveness ratio

LRTI: lower respiratory tract infection

MET: metabolic equivalent of task

MVPA: moderate-to-vigorous physical activity

QALY: quality-adjusted life years

UI: uncertainty interval

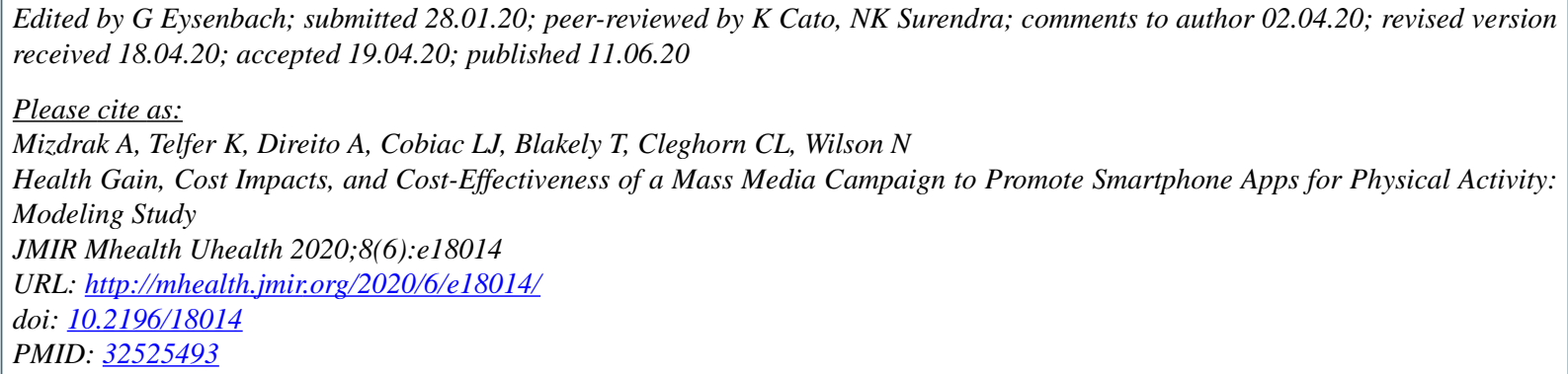

(C)Anja Mizdrak, Kendra Telfer, Artur Direito, Linda J Cobiac, Tony Blakely, Christine L Cleghorn, Nick Wilson. Originally published in JMIR mHealth and uHealth (http://mhealth.jmir.org), 11.06.2020. This is an open-access article distributed under the terms of the Creative Commons Attribution License (https://creativecommons.org/licenses/by/4.0/), which permits unrestricted use, distribution, and reproduction in any medium, provided the original work, first published in JMIR mHealth and uHealth, is properly cited. The complete bibliographic information, a link to the original publication on http://mhealth.jmir.org/, as well as this copyright and license information must be included. 